\title{
PHOTODEGRADATION OF INSECTICIDE DIAZINON UNDER SIMULATED SOLAR LIGHT IRRADIATION CONDITIONS AND IDENTIFICATION OF PHOTOPRODUCTS
}

\author{
NIKNAFS, B.N. ${ }^{1}{ }^{*}-$ AHMADI, A. ${ }^{1}-$ HAJIKHANI, R. ${ }^{2}-$ MIANJY, J.G. ${ }^{3}-$ \\ GHORBANKHANI, Z. ${ }^{3}$ \\ ${ }^{I}$ Department of Chemistry, Faculty of Science, Islamic Azad University, Karaj-Baranch \\ End of rajaee shahr, moazzen and esteghlal blvd., PO Box: 31458-313 Karaj-Iran \\ (phone: 0098-912-6950104; fax: 0098-21-44537493) \\ ${ }^{2}$ Departement of Biology, Faculty of Science, Islamic Azad University, Karaj-Baranch \\ ${ }^{3}$ Abyek Chemical Complex, Research and Development Laboratories, Abyek-Iran \\ *Corresponding author \\ e-mail:niknafs22@yahoo.com \\ (Received $29^{\text {th }}$ July 2011; accepted $29^{\text {th }}$ January 2013)
}

\begin{abstract}
The photodegradation of the organophosphorus insecticide diazinon with a high probability to contaminate aquatic environments under simulated solar light irradiation conditions on natural water of a river in North of Iran has been studied. During exposure to solar natural light, diazinon is broken down and produced photoproducts in environment. The degradation of the insecticide was a 32 hour process and included the formation of several intermediates that were identified using GC/ion-trap mass spectrometry with EI or CI in positive and negative ionization mode and HPLC/mass spectrometry. On the basis of the structurally identified photoproducts a possible degradation pathway is proposed for the photolysis of diazinon in natural water. Since primarily hydroxy derivatives were identified in this solution, the mechanism of degradation was probably based on hydroxyl radical attack. The initial oxidative pathways of the degradation of diazinon involved the substitution of sulfur by oxygen on the $\mathrm{P}=\mathrm{S}$ bond, cleavage of the pyrimidine ester bond, and oxidation of the isopropyl group. Exact mass measurements of the derivatives allowed the elemental formula of the molecules to be determined confidently.
\end{abstract}

Keywords: Contamination, Environmental, Photolysis, Organophosphorus

\section{Introduction}

Diazinon [O,O-diethylO-(2-isopropyl-6-meth- ylpyrimidin-4-yl) thiophosphate] (Figure 1) is an organo-phosphorus insecticide with widespread agricultural. The primary environmental concerns associated with its use are bird kills, contamination of surface water, and impacts on aquatic species. Diazinon and its metabolites have been encountered during monitoring studies in various aquatic systems all over the world (Dubus et al., 2000). Additionally, high diazinon residues have been found in urban water- ways and effluents from sewage treatment plants (Bailey, Deanovic et al., 2000; Bailey, Kraddoi et al., 2000). Toxic effects of diazinon are due to the inhibition of acetyl cholinesterase. Metabolic studies in animals have shown that the main route of metabolism is oxidation, and several metabolites with higher acetyl cholinesterase inhibition activity have been identified (Roberts and Hutson, 1999). In the environment, diazinon appears to be mobile and persistent enough to significantly impact water resources. The abiotic environmental fate of diazinon has been well studied previously; it is stable at neutral waters, while it is rapidly hydrolyzed at acidic $\mathrm{pH}(\mathrm{Ku}$ and Chang, 
1998). Hydrolysis products have been identified as 2-Isopropyl-6-methyl-pyrimidin-4ol and diethyl thiophosphate (Mansour et al., 1999). Diazinon is slowly photodegraded in distilled water under sunlight, while in natural waters the process is significantly faster (Scheunert et al., 1993; Lacorte et al., 1995). 2-Isopropyl-6-methylpyrimidin-4-ol has been identified as the main photoproduct (Ku and Chang, 1998). Photolysis studies of diazinon in soil aqueous suspensions under UV light have shown that the main transformation products are its oxygen analogue, diethyl 2-isopropyl-6methylpyrimidin-4-yl phosphate (diazoxon), its isomer O,O-diethyl S-(2-isopropyl-6methylpyrimidin-4-yl) thiophosphate) (isodiazinon), and O,O-diethyl O-[2-(1-hydroxy1-methylethyl)-6-methylpyrimidin-4-yl] thiophosphate (hydroxydiazinon) (Mansour et al., 1999). Because diazinon transformation products are more polar than the parent compound, they may be consequently more water soluble, more mobile, and have a greater potential to leach from soil. Therefore, these compounds would probably be found in surface and ground water at higher concentrations than the parent compound.

Since the formation of highly toxic reaction intermediates is possible, identification of the degradation products is essential (San et al., 2002). The purpose of this study was to analyze the photodegradation products of diazinon using GC/ion-trap mass spectrometry and HPLC/ mass spectrometry. For identification, structural data were obtained on an ion trap mass spectrometer following electron impact ionization (EI), positive ion chemical ionization (CI) and negative ion chemical ionization (NCI). These data were complemented with exact mass measurements on both precursor and fragment ions obtained using a mass spectrometer. A degradation pathway for diazinon is proposed based on the identified intermediates and also compared with the metabolic pathways in living organisms.

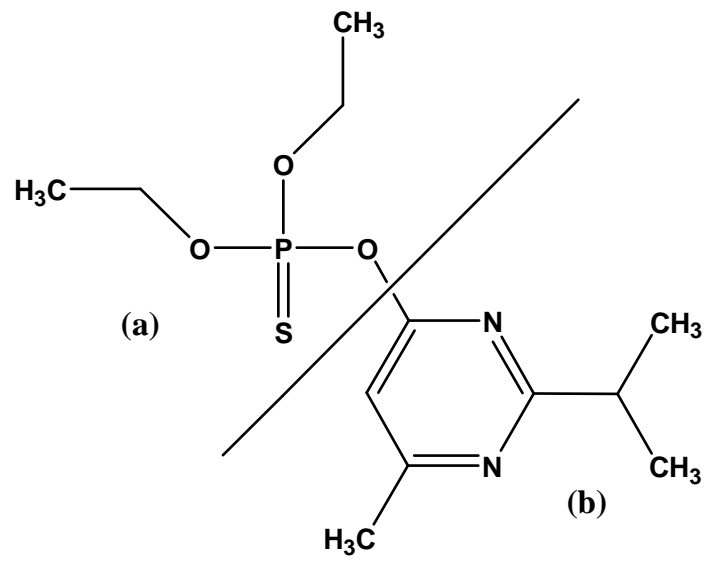

Figure 1. Molecular structure of the diazinon. Thiophosphate moiety (a) and pyrimidine group (b) are shown

\section{Materials and methods}

\section{Chemicals and reagents}

Diazinon technical $(95.0 \%)$ and granules $10 \%$ were a gift from Abyek Chemical Complex.

Analytical grade standard of diazinon of high purity was obtained from Fluka and was used without further purification and all the chemicals and solvents were obtained from E-Merck (Darmstadt, Germany). 


\section{Water sampling}

Natural waters used in the experiments were collected from the Mazandaran province in North Iran and was natural water of Babolrood River. The natural water sample collected from the top meter of water body in 2.5-L pre-cleaned amber glass bottle and stored at $4{ }^{\circ} \mathrm{C}$ prior to use. Water sample was used without previous treatment and filtration. Physicochemical characteristics of sample of Babolrood River natural water are given in Table 1.

Table 1. Physicochemical properties of the selected natural waters

\begin{tabular}{c|c|c|c|c|c|c}
\hline Water type & $\mathbf{p H}$ & $\begin{array}{c}\text { Conductivity } \\
(\boldsymbol{\mu S} / \mathbf{c m})\end{array}$ & $\begin{array}{c}\mathbf{T D S}^{\mathbf{1}} \\
(\mathbf{m g} / \mathbf{L})\end{array}$ & $\begin{array}{c}\mathbf{T O C}^{2} \\
(\mathbf{m g} / \mathbf{L})\end{array}$ & $\begin{array}{c}\text { Salinity } \\
\left({ }^{\circ} / \mathrm{oo}\right)\end{array}$ & $\begin{array}{c}\mathbf{N o}_{\mathbf{3}}^{-} \\
(\mathbf{m g} / \mathbf{L})\end{array}$ \\
\hline Babolrood River & 7.81 & 382 & 208 & 2.93 & 0.4 & 3.28 \\
\hline
\end{tabular}

${ }^{1}$ TDS: Total Dissolved Solids, ${ }^{2}$ TOC: Total Organic Carbon

\section{Photolysis in natural waters under simulated solar irradiation}

The photochemical stability of diazinon was tested using a Sunset CPS+ photo simulator from Heraeus (Hanau, Germany), equipped with a xenon arc lamp (1500 W) and special glass filters restricting the transmission of wavelength below $290 \mathrm{~nm}$. The light source was on the top of the reactor and average irradiation intensity of $750 \mathrm{~W} / \mathrm{m}^{2}$ was maintained throughout the experiments measured by an internal radiometer. Chamber and black panel temperatures were regulated by pressurized air-cooling circuit and monitored using thermocouples supplied by the manufacturer. The temperature of samples did not exceed $25{ }^{\circ} \mathrm{C}$ using tap water cooling circuit for the UV-reactor. The distance between the irradiated solutions and the lamps was $17 \mathrm{~cm}$. Irradiation experiments were carried out by exposing $200 \mathrm{ml}$ of aqueous solution of diazinon (20 $\mathrm{mg} / \mathrm{L}$ ) containing $0.2 \%$ sodium azide (for biological degradation resistance) under artificial solar irradiation. During irradiation, the samples were magnetically stirred. All experiments were carried out at room temperature and $\mathrm{pH}$ 6. A dark control experiment was also conducted in this experiment. The treated water sample was processed for diazinon photodegradation on 32 hour after treatment that almost is equal with sunlight natural irradiation at 8 sunny days.

\section{Extraction procedure}

Treated water samples $(200 \mathrm{ml})$ were taken in a separator funnel and $10 \mathrm{~g}$ sodium chloride was added. The diazinon residues and probably photoproducts were extracted by liquid-liquid partitioning thrice with $15 \%$ dichloromethane in acetone. The extract is passed through anhydrous sodium sulphat to remove residual water. Combined the organic layers and concentrated to near dryness on a rotary vacuum flash evaporator followed by nitrogen gas manifold evaporator. The process was repeated thrice after adding $5 \mathrm{ml}$ acetone in order to eliminate the traces of dichloromethane. The final volume $(2 \mathrm{ml})$ was made in acetone for analysis. The final sample was stored in the dark place while awaiting analysis. 


\section{Analytical procedures}

\section{HPLC analysis}

Analyses were carried out using a Waters (Milford, MA) Model TM 600 gradient pump and a 717 auto sampler. Data were processed using Waters Millenium software (version 2.0). The analytical column was Waters $\mathrm{C}_{18}, 4.6 \times 250 \mathrm{~mm}$, the mobile phase was isocratic acetonitrile/water, 70:30 (v/v), at a flow rate of $1 \mathrm{~mL} / \mathrm{min}$, and the eluate was monitored at $254 \mathrm{~nm}$. The irradiated solutions were filtered through $0.45 \mu \mathrm{m}$ Millipore Millex-LCR filters before HPLC analysis. The injection volume was $20 \mu \mathrm{L}$.

\section{GC/MS analysis}

A Hewlett-Packard system consisting of a 5890 GC system equipped with electron capture detector (ECD) and capillary column HP-1 (30 $\mathrm{m} \times 0.32 \mathrm{~mm}$ i.d., $0.25 \mu \mathrm{m}$ film thickness of 5\% diphenyl / 95\% dimethyl polysiloxane), a 5971 mass spectrometer. Chromatographic data were monitored by Xcalibur ${ }^{\circledR} 1.4$ software. The helium carrier gas velocity was $30 \mathrm{~cm} / \mathrm{s}$, the injector temperature was $210{ }^{\circ} \mathrm{C}$, and the transfer line temperature was set at $275^{\circ} \mathrm{C}$. The oven program was $1 \mathrm{~min}$ at $60{ }^{\circ} \mathrm{C}, 20^{\circ} \mathrm{C} / \mathrm{min}$ to $80^{\circ} \mathrm{C}, 5{ }^{\circ} \mathrm{C} / \mathrm{min}$ to $196{ }^{\circ} \mathrm{C}$, and $20^{\circ} \mathrm{C} / \mathrm{min}$ to $270{ }^{\circ} \mathrm{C}$ (10 min). The mass spectrometer detector was tuned by maximum sensitivity autotune. Mass spectra database searches were carried out using the Wiley (New York, NY) Registry of Mass Spectral Data, 6th edition, and the NIST Mass Spectral Search Program version 1.6d.

\section{Results}

The intermediate products formed in this photodegradation of diazinon in the aqueous solution after 32 hours were investigated by HPLC/GC/MS analysis. Six products were identified by the molecular ion and mass fragment ions, and also through comparison with NIST library data. The structures of the six photoproducts are represented in Figure 2, together with the parent compound. The similarities of these compounds to the NIST library data were more than $85 \%$. By interpreting the mass spectra, the product no. 1 (2-isopropyl-6-methyl-pyrimidin-4-ol, IMP) was formed from diazinon due to the cleavage of $\mathrm{P}-\mathrm{O}$ (pyrimidine ring) bond. The product no. 2 (diazoxon) was found to be the product which was substituted the $\mathrm{S}$ atom to $\mathrm{O}$ atom. Further hydroxyl radical attack could yield to hydroxyl derivative of diazoxon (product no. 3). The product nos. 4 and 6 were formed due to hydroxylation of isopropyl group on diazinon. The product no.5 was formed by further oxidizing hydroxydiazinon (product no. 4) on the isopropanol group. In addition to these six compounds, other degradation products still possibly would exist in the photodegradation system but were not detected because of their low concentration, extraction efficiency and limited sensitivity in GC/MS.

\section{Discussion}

Based on the intermediate products listed in Table 2, as well as the literature data (Kouloumbos et al., 2003; Sakkas et al., 2005), the possible degradation pathway for diazinon is proposed in Scheme 1. As can be seen, two possible degradation pathways are proposed (Figure 1): one pathway involved the cleavage of the $\mathrm{P}-\mathrm{O}$ (pyrimidine group) bond yielding IMP. In the photodegradation process, loss of the pyrimidine 
group probably occurred either through oxidative desulfuration by $\mathrm{OH}$ radical attack (Atkinson et al., 1989) on the thiono group to give diazoxon followed by hydrolysis, or through an oxidation mechanism acting directly on diazinon.

Table 2. Identified products by GC/MS in the photocatalytic degradation of dizainon

\begin{tabular}{c|c|c|c|c}
\hline $\begin{array}{c}\text { Product } \\
\text { No. }\end{array}$ & RT (min) & M.W. & $\begin{array}{c}\text { Characteristic ions } \\
\mathbf{( m / \mathbf { z } )}\end{array}$ \\
\hline 1 & 26.1 & 152 & $137,152,124$ & Compound \\
2 & 29.9 & 288 & $137,151,273$ & Diazoxon \\
Diazinon & 30.5 & 304 & $137,152,179$ & Diazinon \\
3 & 32.0 & 304 & $111,153,289$ & Hydroxydizoxon \\
4 & 32.7 & 320 & $153,169,320$ & Hydroxydiazinon \\
5 & 33.7 & 304 & $153,180,199$ & Diazinon methyl ketone \\
6 & 35.2 & 320 & $151,122,195$ & 2-hydroxydiazoxon \\
\hline
\end{tabular}

These oxidative mechanisms have already been observed for most thiophosphates in metabolic studies (Raymond Yang et al., 1971). In the second pathway, the thiophosphoric moiety of diazinon was preserved. Hydroxylation of the primary or secondary carbon atoms of the isopropyl group gave hydroxydiazinon or 2hydroxydiazinon, respectively, which after further oxidation led to diazinon aldehyde and diazinon methyl ketone.

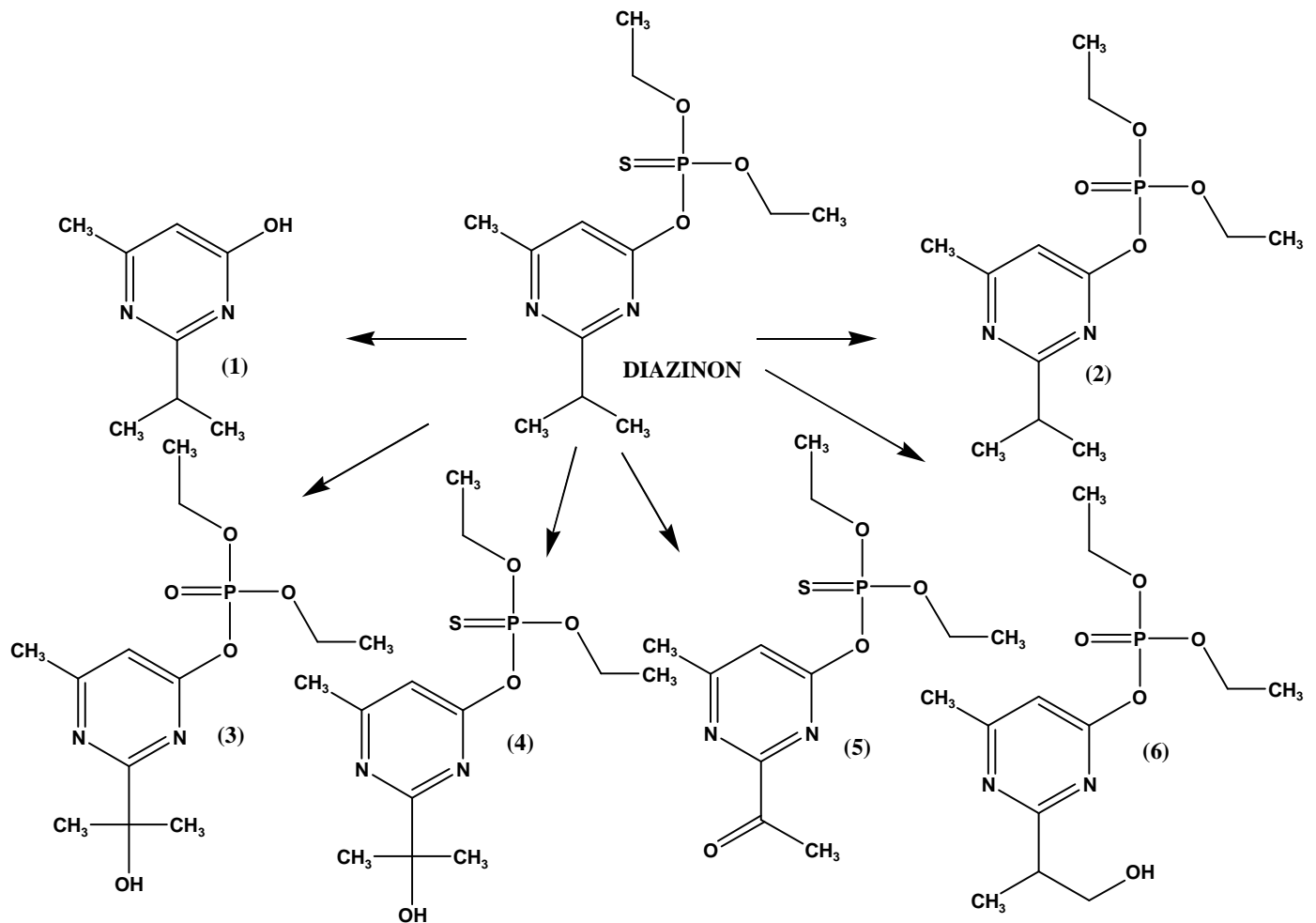

Figure 2. Scheme of the proposed photodegration pathway for diazinon: 2-isopropyl-6-methylpyrimidin-4-ol, (IMP) (1), dizoxon (2), hydroxydizoxon (3), hydroxydiazinon (4) diazinon methyl ketone (5), 2-hydroxydiazoxon (6) 
A similar transformation pathway was observed following for the oxygen analogue diazoxon formed by oxidation of the $\mathrm{P}=\mathrm{S}$ bond of diazinon to a $\mathrm{P}=\mathrm{O}$ bond which led to the formation of the hydroxylated derivatives. IMP is the hydrolysis product of diazinon detected in natural waters while photochemical transformation of the parent molecule yields the production of diazoxon and hydroxydiazinon, respectively (Mansour, 1999). Hydroxylated metabolites of diazinon including hydroxydiazoxon have also been observed in metabolism studies (Pisani-Borg, 1996).

\section{Conclusions}

Information on degradation products is necessary to understand the environmental fate of pesticides and to establish important degradation pathway, which will allow us to get a better knowledge of the transformation of target compounds in the environment. Moreover, the study of contaminant photochemical behavior is a key issue in terms of the formation of toxic transformation products. The photodegradation of diazinon under simulated solar light irradiation conditions on natural water of a river in North of Iran has been observed to proceed essentially through a hydroxylation mechanism occurring rapidly by attack of the photochemically generated $\mathrm{OH}$ radicals. The main transformation intermediates identified were oxidation products of the isopropyl group of diazinon and its oxygen analogue diazoxon. Loss of the thiophosphoric moiety yielded the pyrimidinol IMP. The results reported here show that the combination of HPLC/GC/MS with EI, positive and negative ions and exact mass measurements represent a powerful analytical approach for the confirmation of the molecular structure of photodegradation intermediates. These photoproducts are extremely stable and actually more toxic than the parent compound. Toxicity and persistence of photoproducts indicate that these compounds should be considered along with the metabolites in residue and toxicology evaluations.

\section{REFERENCES}

[1] Albanis, T., Hela, D., Sakellarides, T., Konstantinou, I. (1998): Monitoring of Pesticide Residues and Their Metabolites in Surface and Underground Waters of Imathia (N.Greece) by Means of Solid-Phase Extraction Disks and Gas Chromatography. - J. Chrom. A 823: 59-71.

[2] Atkinson, R., Aschmann, S., Arey, J., McElroy, P., Winer, A. (1989): Product formation from the gas-phase reactions of the hydroxyl radical with O,O,O-trimethyl phosphorothioate $[(\mathrm{CH} 3 \mathrm{O}) 3 \mathrm{PS}]$ and O,O,S-trimethyl phosphorodithioate [(CH3O)2P(S)SCH3]. - Environ. Sci. Technol. 23: 243-244.

[3] Bailey, H., Deanovic, L., Reyes, E., Kimball, T., Larson, K., Cortright, K., Connor, V., Hinton, D. (2000): Diazinon and Chlorpyrifos in Urban Waterways in Northern California, USA. - Environ. Toxicol. Chem. 19: 82-87.

[4] Bailey, H., Kraddoi, R., Elphick, J., Mulhall, A., Hunt, P., Tedmanson, L., Lovell, A. (2000): Whole Effluent Toxicity of Sewage Treatment Plants in the Hawkesbury-Nepean Watershed, New South Wales, Australia, to Ceriodaphnia dubis and Selenastrum capricornutum. - Environ. Toxicol. Chem. 19: 72-81.

[5] Dubus, I., Hollis, J., Brown, C. (2000): Pesticides in Rainfall in Europe. - Env. Pollut. 110: 331-344. 
[6] Garcia, S., Ake, C., Clement, B., Huebuer, H., Donnelly, K., Shalat, S. (2001): Initial Results of Environmental Monitoring in the Texas Rio Grande Valley. - Environ. Int. 26: 465-474.

[7] Kouloumbos, V.N., Tsipi, D.F., Hiskia, A.E., Nikolic, D., van Breemen, R.B. (2003): Identification of Photocatalytic Degradation Products of Diazinon in $\mathrm{TiO}_{2}$ Aqueous Suspensions Using GC/MS/MS and LC/MS with Quadrupole Time-of-Flight Mass Spectrometry. - J. Am. Soc. Mass Spectrom. 14: 803-817.

[8] Ku Y., Chang, J. (1998): Effect of Solution $\mathrm{pH}$ on the Hydrolysis and Photolysis of Diazinon in Aqueous Solution. - Water Air Soil Pollut. 108: 445-456.

[9] Lacorte, S., Lartiges, S., Garrigues, P., Barcelo, D. (1995) Degradation of Organophosphorus Pesticides and Their Transformation Products in Estuarine Waters. Environ. Sci. Technol. 29: 431-438.

[10] Mansour, M., Feicht, E., Behechti, A., Schramm, K.W., Kettrup, A. (1999): Determination Photostability of Selected Agrochemicals in Water and Soil. Chemosphere 39: 575-585.

[11] Pisani-Borg, E., Cuany, A., Brun, A., Amichot, M., Fournier, D., Berge, J. (1996): Oxidative Degradation of Diazinon by Drosophila: Metabolic Changes Associated with Insecticide Resistance and Induction Pestic. - Biochem. Physiol. 54: 56-64.

[12] Raymond Yang, S.H., Hodgson, E., Dauterman, W.C. (1971): Metabolism in vitro of diazinon and diazoxon in rat liver. - J. Agric. Food Chem. 19: 10-13.

[13] Roberts, T., Hutson, D. (Eds. in Chief) (1999): Metabolic Pathways of Agrochemicals Part 2: Insecticides and Fungicides. - RSC, UK, pp 258-263.

[14] Sakkas, V.A., Dimou, A., Pitarakis, K., Mantis, G., Albanis, T. (2005): $\mathrm{TiO}_{2}$ photocatalyzed degradation of diazinon in an aqueous medium. - Environ. Chem. Lett. 3: $57-61$.

[15] San, N., Hatipoglu, A., Kocturk, G., Cinar, Z.J. (2002): Photocatalytic Degradation of 4Nitrophenol in Aqueous $\mathrm{TiO}_{2}$ Suspensions: Theoritical Prediction of the Intermediates.Photochem. - Photobiol. A. Chem. 146: 189-197.

[16] Scheunert, I., Mansour, M., Dorfler, U., Schroll, R. (1993) Fate of Pendimethalin, Carbofuran, and Diazinon under Abiotic and Biotic Conditions. - Science Total Environ. 132: 361-369. 